\title{
CARACTERÍSTICAS DAS FIBRAS MUSCULARES DO L. DORSIE QUALIDADE DA CARNE DE SUÍNOS DE QUATRO LINHAGENS
}

\author{
LONGISSIMUSDORSIMIOFIBRE CHARACTERISTICS AND MEAT QUALITY \\ IN FOUR PORK LINES
}

\author{
Borosky, J.C. ${ }^{1}$, Rocha, M.A. ${ }^{1}$, Oba, A. ${ }^{1}$, Pinheiro, J.W. ${ }^{1}$, Bridi, A.M. ${ }^{1}$ e Silva, C.A. ${ }^{1}$ \\ ${ }^{1}$ Universidade Estadual de Londrina. Centro de Ciências Agrárias. Departamento de Zootecnia. Cx. Postal \\ 6001. CEP 86051-970. Londrina, PR. Brasil. casilva@uel.br
}

\section{PalaVRas chaVe ADicionais}

Células musculares. Perda de água.

\section{RESUMO}

O objetivo desse trabalho foi analisar as características miofibrilares de suínos de quatro linhagens distintas e correlacioná-las com a qualidade de carne. Foram utilizados 48 animais (24 machos castrados e 24 fêmeas) provenientes de 4 linhagens, representando os tratamentos experimentais: linhagem melhorada comercialmente, selecionada para crescimento e produção de carne magra; linhagem melhorada comercialmente, selecionada para fins de prolificidade; animais oriundos do cruzamento Landrace $x$ Large White; e linhagem não melhorada geneticamente. Foram avaliados o comprimento do sarcômero, o tipo de fibra muscular, o número e o diâmetro das células musculares e as características de qualidade da carne (cor, marmoreio e perda de água por gotejamento). $\mathrm{O}$ delineamento experimental foi inteiramente casualizado em arranjo fatorial $4 \times 2$ (4 padrões genéticos e 2 sexos), sendo cada animal uma repetição. Os animais selecionados para deposição de carne, os melhorados para prolificidade $e$ os animais cruzados Landrace $x$ Large White apresentaram maior número de células musculares $(p<0,05)$ que os animais sem seleção. Os animais Landrace $x$ Large White apresentaram o maior diâmetro celular $(p<0,05)$; os animais sem seleção e os selecionados para prolificidade apresentaram as menores médias. Não houve diferença entre as linhagens para o comprimento de sarcômero. Os animais selecionados para prolificidade tiveram menor porcentagem de fibras glicolíticas $(p<0,05)$ e maior porcentagem de fibras intermediárias que as

Recibido: 26-10-07. Aceptado: 17-11-08.

\section{Additional KEYWORdS}

Muscle cell. Dripping loss.

demais linhagens $(p<0,05)$. Os animais selecionados para deposição de carne e os animais selecionados para prolificidade apresentaram os maiores $(p<0,05)$ e os menores $(p<0,05)$ valores para a perda de água por gotejamento, respectivamente. Os animais sem seleção apresentaram a maior taxa de marmoreio $(p<0,05)$ e carne mais escura $(p<0,05)$, enquanto que os animais selecionados para deposição de carne apresentaram a menor taxa de marmoreio $(p<0,05)$. Os machos castrados apresentaram carne mais clara que as fêmeas $(p<0,05)$. A análise da correlação indicou que o número de células musculares está associado positivamente com a perda de água por gotejamento e a luminosidade da carne. O número e o tipo de fibras do músculo estão relacionados com as características de qualidade da carne. Genéticas com mais fibras musculares têm menor taxa de gordura intramuscular e apresentam carne mais clara e com menor capacidade de retenção de água, mas não foi observado correlação entre número de fibras musculares e freqüência de fibras glicolíticas.

\section{SUMMARY}

The aim of this paper was to analyze the myofiber characteristics of four distinct genetic pork groups and correlate them with the meat quality. 46 animals ( 23 barrows and 23 females) from four genetic lines were used, representing the experimental treatments: high-lean commercial cross-bred line; commercial cross-bred line 
selected for ends of prolificacy, non selected genetic line and crossbred animals (Landrace $x$ Large White). Were analyzed the sarcomere length, myofiber differentiation, myofiber number and diameter and meat quality (colour, marbling and dripping loss). It was used a complete randomized design with a 4x2 factorial arrangement (4 genetic lines and 2 sexes). The high-lean commercial cross-bred line, commercial cross-bred line selected for ends of prolificacy and Landrace $x$ Large White animals presented greater myofiber number than non selected animals $(p<0.05)$. Landrace $x$ Large White animals presented the greatest cell diameter and non selected animals and commercial cross-bred line selected for ends of prolificacy animals presented the smallest averages for this trait $(p<0.05)$. There were no differences among genetic lines for sarcomere length. The commercial cross-bred line selected for ends of prolificacy animals had less glicolitic fibers percentage and more intermediate fiber percentage $(p<0.05)$ than the other genetic groups. The high-lean commercial cross-bred line and commercial cross-bred line selected for ends of prolificacy had the greatest $(p<0.05)$ and the smallest $(p<0.05)$ dripping loss values, respectively. Non selected animals presented the greatest marbling value and the darkest meat $(p<0.05)$, while they showed more intramuscular-fat than high-lean commercial cross-bred line animals $(p<0.05)$ and showed the darker meat $(p<0.05)$. Barrows presented lighter paler meat than females. The correlation analysis indicates that the myofiber number was positively associated with dripping loss values and lightness. It also indicates that muscle with greater glicolitic fiber present greater marbling value. In this way we conclude that the myofiber number and type are related with meat quality characteristics. Breeds with greater myofiber number have less intramuscular fat, lighter muscles and smaller water holding capacity, but it was not observed correlation among myofiber number and glicolitic fiber percentage.

\section{INTRODUÇÃO}

A produção de carcaças com alto rendimento em carne magra e de boa qualidade sensorial e industrial é o principal objetivo da atual criação de suínos, demandando a seleção intensa de animais de elevado desenvolvimento muscular.
A característica número de fibras musculares, neste sentido, está relacionada com um crescimento rápido e eficiente (Dwyer et al., 1993) e negativamente com a deposição de gordura (Seidman et al., 1989), sendo considerada um importante indicador do potencial de desempenho (Handel e Stickland, 1988). No entanto, as condutas de redução da espessura de toucinho e de aumento do rendimento de carne magra na carcaça têm provocado depreciação na qualidade da carne, comprometendo principalmente o teor de gordura intramuscular.

De Vries et al. (1994), citados por Irgang (1997), relataram que as correlações fenotípicas e genéticas entre o rendimento de carne e a gordura intramuscular são negativas e moderadas, observando-se menor teor de gordura intramuscular em raças com alto rendimento de carne.

Segundo Ryu e Kim (2005), o tipo de fibra muscular tem também grande influência sobre a qualidade da carne, dada à relação que apresenta com o metabolismo post-mortem. Animais mais musculosos (Ashmore et al., 1972; Powell e Aberle, 1981; Wegner et al., 2000) e com fibras de maior diâmetro (Larzul et al., 1997) têm maior proporção de fibras glicolíticas em sua musculatura, apresentando carne mais clara (Larzul et al., 1997; Ryu e Kim, 2005) e com menor capacidade de retenção de água (Ryu e Kim, 2005). Portanto, de qualidade inferior.

Como uma característica de moderada a alta herdabilidade, o tipo de fibra pode ser submetido a processos de seleção diretos, diminuindo a freqüência das fibras glicolíticas na musculatura sem comprometimento do desenvolvimento do animal(Larzuletal., 1997).

Embora existam muitos aspectos histológicos do músculo com efeitos claros sobre a qualidade da carne, algumas características ainda guardam polêmica. Assim, o objetivo desse estudo foi correlacionar as características histológicas do músculo Longissimus dorsi com parâmetros relacionados com a qualidade de carne em suínos de diferentes linhagens.

Archivos de zootecnia vol. 59, núm. 226, p. 278. 


\section{CARACTERÍSTICAS DAS FIBRAS MUSCULARES E A QUALIDADE DA CARNE SUÍNA}

\section{MATERIALE MÉTODOS}

Foram estabelecidos 4 grupos experimentais, representados por 4 padrões (grupos) genéticos diferentes, formados por leitões provenientes de 4 granjas suinícolas.

Quarenta e oito animais (metade machos castrados e metade fêmeas) foram selecionados, tendo como base o peso vivo correspondente ao peso médio da leitegada ao desmame (realizado aos 21 dias em média). Foram escolhidos, portanto, 12 leitões de cada granja (de cada genética), oriundos de várias leitegadas, definindo os seguintes tratamentos experimentais: híbridos comerciais melhorados para crescimento/produção de carne magra; híbridos comerciais melhorados para fins de prolificidade, animais resultantes de cruzamentos entre as raças Large White x Landrace; e animais de linhagem não melhorada geneticamente.

Os animais foram alojados em 24 baias ( 2 suínos de mesmo sexo por unidade) desde o desmame até os $100 \mathrm{~kg}$ de peso vivo aproximadamente, formando 4 grupos de 12 animais (6 castrados e 6 fêmeas) de cada padrão genético. Durante todo o período experimental os grupos receberam rações isonutrientes, oferecidas à vontade, formuladas de acordo com as exigências estabelecidas pelo NRC (1998).

Foram avaliados os parâmetros histológicos, número e diâmetro das fibras musculares do Longissimus dorsi, tipos de células musculares, comprimento do sarcômero e características indicativas de cor, marmoreio e perda de água na carne.

O delineamento experimental foi inteiramente casualizado em arranjo fatorial 4 x 2 (4 padrões genéticos e 2 sexos). Cada suíno foi considerado uma repetição.

Ao atingirem o peso médio de $100,00 \pm$ $3,45 \mathrm{~kg}$ os animais foram abatidos em um frigorífico comercial. Previamente ao abate, os suínos foram submetidos ao jejum de sólidos por 12 horas. O tempo do transporte foi em torno de 1 hora e os animais permaneceram nas baias de descanso no frigorífico por aproximadamente 1 hora. A insensibilização, precedendo o sacrifícío, foi por corrente elétrica, utilizando-se o equipamento Petrovina ${ }^{\circledR}$ IS 2000 com 2 eletrodos, aplicando-se choque elétrico (350 volts e 1,3 amperes) por aproximadamente 3 segundos. Os animais foram abatidos pelo corte da veia jugular e submetidos à sangria na horizontal.

Após o abate, escaldagem, evisceração, corte longitudinal e pesagem das carcaças, a meia carcaça direita foi separada, serrada na altura da última costela e uma amostra do músculo Longissimus dorsi, de aproximadamente $8 \mathrm{~cm}$ de largura e $4 \mathrm{~cm}$ de comprimento, foi retirada a $6 \mathrm{~cm}$ da linha da coluna. Os 2 primeiros centímetros do corte foram utilizados para a análise de comprimento de sarcômero e o restante foi utilizado para a análise de freqüência dos tipos de fibras musculares e para a diferenciação do tipo de fibra.

Para a avaliação histológica foi utilizado o programa Image-Pro Plus, versão 4.5.1.22, e um Scanner HP 4c, para mensurar a área total do músculo. Para determinar o número de fibras musculares do músculo Longissimus dorsi utilizou-se uma Câmera digital Pro-series 3-chipcolor e um microscópio Olympus BX 50. Para estimar o número de fibras musculares foi feita a contagem aleatoriamente de 13 campos de cada lâmina. Assim, conhecida a área total do músculo e as áreas dos campos foi possível estimar o número total de miofibrilas de cada músculo.

Para a mensuração do comprimento do sarcômero as amostras dos músculos foram fotografadas em microscopia eletrônica de transmissão no aumento de $1950 \mathrm{X}$, e com o auxílio de um analisador de imagens foram mensurados 25 sarcômeros escolhidos aleatoriamente por foto, totalizando 125 sarcômeros por animal.

Para a diferenciação celular as amostras do Longissimus dorsi foram submetidas à técnica do NADH que diferencia as células em células de metabolismo glicolítico e de contração rápida, de metabolismo oxidativo 
e de contração lenta e células intermediárias de metabolismo glicolítico-oxidativo. As lâminas foram analisadas em microscopia óptica e para estimar o número de fibras musculares de cada tipo foi feita a contagem aleatória de 6 campos de cada lâmina, em objetiva de 10 .

As carcaças foram acondicionadas em câmara fria a uma temperatura média de $2 \pm$ $1^{\circ} \mathrm{C}$ por 24 horas, quando então foi retirada uma amostra do Longissimus dorsi, na meia carcaça esquerda, tendo como referência a última costela em direção à porção cranial do animal. Em seguida a amostra foi armazenada em sacos plásticos individuais, acondicionados em caixa térmica, para análise posterior.

No laboratório de Nutrição Animal da Universidade Estadual de Londrina, as amostras de L. dorsi foram cortadas em fatias de $1 \mathrm{~cm}$ de espessura. A primeira fatia foi utilizada para a avaliação da cor e para a perda de água por gotejamento, a segunda utilizada para avaliação do marmoreio e a terceira utilizada para a contagem celular.

A perda de água por gotejamento foi avaliada pela técnica de Boccard et al. (1981). O grau de marmoreio foi determinado com auxílio de padrões fotográficos, utilizandose as escalas de valores numéricos em que foram atribuídas notas de 1 a $5(1=$ traços de marmoreio e $5=$ marmoreio abundante). A cor foi determinada através do aparelho colorímetro portátil MINOLTA CR10. Os componentes $L^{*}, a^{*}$ e $b^{*}$ foram expressos no sistema de cor CIELAB.

Para a contagem e mensuração do diâmetro celular do músculo Longissimus dorsi, foi utilizada uma câmera digital Proseries 3-Chipcolor e um Microscópio Olympus BX 50, para a captura dos campos. Para estimar o número de fibras musculares foi feita a contagem aleatória de 13 campos.

Os resultados foram submetidos à análise de variância utilizando o programa estatístico SAEG (UFV, 1997) e as médias foram comparadas utilizando o teste de Duncan ao nível de 5\% de significância e a análise de correlação foi realizada utilizando-se o teste de correlação de Pearson.

\section{RESUTADOSEDISCUSSÃO}

Os animais apresentaram aos $100 \mathrm{~kg}$ de peso vivo, as seguintes idades médias ao abate, 140,$9 ; 143,8 ; 141,6$ e 154,7 dias, respectivamente, para linhagem melhorada para carne, linhagem melhorada para prolificidade, cruzados Landrace x Large White e sem seleção. O grupo sem seleção diferiu $(\mathrm{p}<0,05)$ dos demais grupos para o parâmetro, entretanto não foi observada diferença entre os outros tratamentos.

Os resultados referentes ao número e ao diâmetro das células e ao comprimento dos sarcômeros do músculo Longissimus dorsi estão apresentados na tabela $\mathbf{I}$.

Os híbridos comerciais e os animais cruzados Large White x Landrace apresentaram maior número de células no músculo Longissimus dorsi que os animais do grupo isento de seleção $(\mathrm{p}<0,05)$.

Esses resultados apresentam-se semelhantes aos obtidos por Ezekwe e Martin (1975) e por Dwyer et al. (1993), que observaram maior número de fibras musculares nos animais de linhagem de crescimento rápido, quando comparados com animais de linhagem de crescimento lento.

Os animais cruzados Large White $\mathrm{x}$ Landrace apresentaram maior diâmetro celular no músculo Longissimus dorsi $(\mathrm{p}<0,05)$ e os animais sem seleção e os híbridos melhorados para prolificidade apresentaram o menor diâmetro $(\mathrm{p}<0,05)$. Os híbridos selecionados para deposição de carne não diferiram dos demais grupos para a característica $(\mathrm{p}>0,05)$. Esses resultados concordam parcialmente com Stickland (1996) e Larzul et al. (1997) que observaram que animais com um maior número de fibras musculares apresentam fibras de menor diâmetro.

Quanto ao comprimento do sarcômero não foram observadas diferenças entre os grupos genéticos e entre os sexos. Para Heinemann et al. (2003) e Silva Sobrinho et 


\section{CARACTERÍSTICAS DAS FIBRAS MUSCULARES E A QUALIDADE DA CARNE SUÍNA}

Tabela I. Médias para as características número e diâmetro celular e comprimento de sarcômero do músculo Longissimus dorsi de suínos de diferentes linhagens e sexos. (Average values for number and diameter of cells and sarcomere length in the Longissimus dorsi muscle from different lines and sexes of swine).

\begin{tabular}{lccc}
\hline Linhagens & $\begin{array}{c}\text { Número de células } \\
(\times 1000)\end{array}$ & $\begin{array}{c}\text { diâmetro celular } \\
\left(\mu \mathrm{m}^{2}\right)\end{array}$ & $\begin{array}{c}\text { Comprimento de } \\
\text { sarcômero }(\mu \mathrm{m})\end{array}$ \\
\cline { 2 - 4 }$\quad$ Híbrido (carne) & $1032,436 \pm 88,78^{\mathrm{a}}$ & $40,58 \pm 3,66^{\mathrm{ab}}$ & $1,70 \pm 0,14$ \\
$\quad$ Híbrido (prolificidade) & $1021,267 \pm 189,08^{\mathrm{a}}$ & $37,43 \pm 2,50^{\mathrm{b}}$ & $1,74 \pm 0,14$ \\
$\quad$ Landrace x Large White & $998,366 \pm 153,02^{\mathrm{a}}$ & $44,00 \pm 7,01^{\mathrm{a}}$ & $1,67 \pm 0,09$ \\
$\quad$ Sem seleção & $870,552 \pm 76,99^{\mathrm{b}}$ & $39,54 \pm 5,60^{\mathrm{b}}$ & $1,81 \pm 0,25$ \\
Sexo & $960,211 \pm 156,85$ & $39,78 \pm 6,21$ & $1,71 \pm 0,20$ \\
$\quad$ Macho castrado & $1004,072 \pm 135,91$ & $41,01 \pm 4,44$ & $1,75 \pm 0,11$ \\
$\quad$ Fêmea & 979144 & 40,30 & 1,73 \\
Média geral & 13,98 & 12,15 & 10,04 \\
CV (\%) & & & \\
\hline
\end{tabular}

Médias seguidas de letras diferentes, na mesma coluna, considerando-se os linhagens e os sexos, diferem pelo teste de Duncan $(p<0,05)$.

al. (2005) que, respectivamente, trabalharam com as espécies bovina e ovina, o padrão genético não influenciou o comprimento do sarcômero. Veríssimo etal. (2008), trabalhando com suínos, também não observaram diferença no comprimento do sarcômero entre linhagens da raça Large White.

Os resultados para a freqüência dos tipos celulares e seus diâmetros estão ex-

\section{pressos na tabela II.}

Os animais selecionados para prolificidade apresentaram menor freqüência para o tipo celular glicolítico de contração rápida (fibras FG) e maior freqüência para o tipo celular oxidativo-glicolítico de contração rápida $(\mathrm{FOG})(\mathrm{p}<0,05)$. As linhagens não diferiram entre si para a freqüência de células de metabolismo oxidativo e contração

Tabela II. Freqüência (\%) das células glicolíticas, oxidativas e intermediárias no músculo L. dorsi para suínos de diferentes linhagens e sexos. (Frequency of glicolitic, oxidative and intermediate cells of $L$. dorsi muscle of swine of different lines and sexes).

\begin{tabular}{lccc}
\hline & Células glicolíticas & Células oxidativas & Células intermediárias \\
\cline { 2 - 4 } Linhagens & $65,45 \pm 3,71^{\mathrm{a}}$ & $20,76 \pm 5,69$ & $13,78 \pm 4,64^{\mathrm{b}}$ \\
Híbrido (carne) & $56,61 \pm 18,22^{\mathrm{b}}$ & $21,56 \pm 5,41$ & $21,83 \pm 5,35^{\mathrm{a}}$ \\
Híbrido (prolificidade) & $20,09 \pm 4,75$ & $14,37 \pm 4,92^{\mathrm{b}}$ \\
Landrace x Large White & $65,54 \pm 18,22^{\mathrm{a}}$ & $20,31 \pm 4,33$ & $10,39 \pm 1,33^{\mathrm{b}}$ \\
Sem seleção & $69,30 \pm 2,50^{\mathrm{a}}$ & & \\
Sexo & & $20,22 \pm 3,67$ & $14,93 \pm 5,12$ \\
$\quad$ Macho castrado & $64,58 \pm 12,62$ & $21,14 \pm 5,57$ & $15,26 \pm 6,92$ \\
Fêmea & $63,60 \pm 7,32$ & 20,68 & 15,09 \\
Média geral & 64,23 & 16,95 & 19,54 \\
CV (\%) & 6,06 & & \\
\hline
\end{tabular}

Médias seguidas de letras diferentes, na mesma coluna, considerando-se os linhagens e os sexos, diferem pelo teste de Duncan $(p<0,05)$. 
lenta $(\mathrm{SO})(\mathrm{p}>0,05)$.

Embora a literatura indique que animais com maior massa muscular (Ashmore et al., 1972) e com fibras de maior diâmetro (Larzul et al., 1997) possuam maior proporção de fibras glicolíticas, este quadro não foi observado. Verificou-se, todavia, que a linhagem com menos fibras musculares apresentou um número de fibras glicolíticas semelhante aos grupos genéticos com mais fibras musculares.

Dal Pai et al. (1997), estudando a freqüência dos tipos de fibras musculares no Longissimus dorsi em três diferentes linhagens suínas (comercial para carne magra, intermediária quanto a deposição de gordura na carcaça e obesa), observaram que os animais comerciais (representados pela raça Large White) apresentaram maior número de fibras glicolíticas (69,2\%) que os demais grupos. Os animais obesos (representados pela raça Sorocaba) apresentaram maior porcentagem de fibras oxidativas $(21,8 \%)$ e os animais da raça Piau (grupo caracterizado como de média deposição de gordura na carcaça) demonstraram maior porcentagem de fibras intermediárias (29,5\%).

Apesar desses autores não terem avaliado o número de células do músculo Longissimus dorsi, os resultados obtidos identificam-se com a hipótese de que animais com maior massa muscular apresentam maior freqüência de fibras glicolíticas, indicando que a participação dos tipos celulares (glicolíticas, oxidativas e intermediárias) pode ser diferente em um mesmo músculo, variando com a base genética do animal, afirmação esta compartilhada por Gil et al. (2006).

Larzul et al. (1997) observaram que a herdabilidade dos tipos de fibras é de moderada a alta, e a herdabilidade da porcentagem de fibras glicolíticas é em torno de 0,58 , apresentando coeficientes elevados de variação, correspondente a $20 \%$ para número total de fibras e a $28 \%$ para a proporção de fibras oxidativas no músculo Longissimus dorsi em suínos da raça Large White.

Os resultados das análises de perda de água por gotejamento, marmoreio e cor estão expressos na tabela III.

Os animais selecionados para deposição de carne apresentaram a maior perda de água por gotejamento $(\mathrm{p}<0,05)$, enquanto que os selecionados para prolificidade apresentaram as menores médias para a característica $(\mathrm{p}<0,05)$. Os animais sem seleção genética e os oriundos do cruzamento Landrace $x$ Large White não diferiram das demais linhagens para o parâmetro avaliado ( $\mathrm{p}>0,05)$.

Os híbridos comerciais melhorados para deposição de carne apresentaram menor taxa de marmoreio, seguidos pelos animais cruzados (Landrace x Large White) e pelos híbridos selecionados para prolificidade. Os animais sem seleção apresentaram a maior taxa de marmoreio $(\mathrm{p}<0,05)$, sendo semelhantes aos híbridos para características reprodutivas. É possível que a taxa de marmoreio do grupo sem seleção tenha sido influenciada pela idade mais elevada ao abate.

A correlação genética e fenotípica entre o rendimento de carne e a gordura intramuscular são negativas e moderadas (De Vries et al., 1994, citados por Irgang, 1997). A menor taxa de marmoreio para animais selecionados para produção de carne magra identifica-se com a afirmação de Handel e Stickland (1988), onde animais com maior rendimento de carne, apresentam menos gordura intramuscular.

Para as características de cor, os animais cruzados (Landrace x Large White) apresentaram carne com mais luminosidade (carne mais clara) e os animais não melhorados menor luminosidade $(\mathrm{p}<0,05)$. Os híbridos comerciais não diferiram dos demais grupos genéticos para a característica $(\mathrm{p}>0,05)$. Para os parâmetros $a^{*}$ e $b^{*}$ não houve diferença estatística entre aos grupos genéticos e também entre os sexos.

Segundo Ryu e Kim (2005), o tipo de fibra tem relação direta com o metabolismo 
Tabela III. Médias para as variáveis: perda de água por gotejamento (PAG), grau de marmoreio (Marm) e valores de a, b e L * para aferição da cor de suínos de diferentes linhagens e sexos. (Average values for drip loss, marble grade and $a, b$ e $L^{*}$ values to color measures of swine of different lines and sexes).

\begin{tabular}{|c|c|c|c|c|c|}
\hline & PAG (\%) & Marm & $a^{*}$ & $b^{*}$ & $L^{*}$ \\
\hline \multicolumn{6}{|l|}{ Linhagens } \\
\hline Híbrido (carne) & $5,77 \pm 1,84^{a}$ & $1,55 \pm 0,65^{c}$ & $3,44 \pm 1,58$ & $9,56 \pm 1,35$ & $52,05 \pm 3,60^{a b}$ \\
\hline Híbrido (prolificidade) & $4,09 \pm 2,06^{b}$ & $2,21 \pm 0,58^{\mathrm{ba}}$ & $4,21 \pm 1,61$ & $9,68 \pm 1,61$ & $50,97 \pm 3,57^{\mathrm{ab}}$ \\
\hline Landrace $\times$ Large White & $5,19 \pm 1,12^{a b}$ & $1,82 \pm 0,75^{b c}$ & $3,33 \pm 1,31$ & $9,78 \pm 1,31$ & $52,59 \pm 3,15^{a}$ \\
\hline Sem seleção & $4,94 \pm 1,37^{a b}$ & $2,54 \pm 0,69^{a}$ & $4,41 \pm 1,25$ & $9,48 \pm 1,60$ & $49,51 \pm 3,66^{b}$ \\
\hline \multicolumn{6}{|l|}{ Sexo } \\
\hline Macho castrado & $5,14 \pm 1,72$ & $1,95 \pm 0,71$ & $4,04 \pm 1,44$ & $9,94 \pm 1,30$ & $52,26 \pm 3,36^{b}$ \\
\hline Fêmea & $4,80 \pm 1,71$ & $2,09 \pm 0,80$ & $3,70 \pm 1,52$ & $9,35 \pm 1,52$ & $50,21 \pm 3,58^{a}$ \\
\hline Média geral & 4,98 & 2,04 & 3,87 & 9,62 & 51,24 \\
\hline CV $(\%)$ & 33,64 & 33,01 & 36,91 & 14,77 & 6,34 \\
\hline
\end{tabular}

Médias seguidas de letras diferentes, na mesma coluna, considerando-se os linhagens e os sexos, diferem pelo teste de Duncan $(p<0,05)$.

post-mortem e por conseqüência efeitos nas características da qualidade da carne, sendo que os músculos com maior porcentagem de fibras glicolíticas produzem carne mais pálida (Larzul et al., 1997; Ryu e Kim, 2005) e com menor capacidade de retenção de água (Ryu e Kim, 2005).

Os resultados observados identificamse parcialmente com estas afirmações, pois as linhagens que apresentaram maior porcentagem de fibras glicolíticas demonstraram menor capacidade de retenção de água. Também os grupos genéticos que apresentaram maior valor de $\mathrm{L}^{*}$, indicando carne mais pálida, foram aqueles que apresentaram maior número de células musculares.

Entre os sexos houve diferença para o valor de $L^{*}$, sendo que os machos castrados apresentaram carne com maior luminosidade $(\mathrm{p}<0,05)$.

$\mathrm{O}$ valor de $\mathrm{L}^{*}$ sugere que animais com mais fibras musculares possuem mais fibras glicolíticas (Ashmore et al., 1972).

$\mathrm{Na}$ tabela IV estão apresentadas as correlações entre o número, o diâmetro das células musculares e o comprimento de sarcômero com os tipos de fibra e com as características qualitativas da carne. Como pode ser observado houve correlação significativa entre as características ligadas à qualidade de carne (perda de água por gotejamento e luminosidade) com o número de células musculares, e correlação da porcentagem de fibras glicolíticas com o marmoreio e da porcentagem de fibras oxidativas com o comprimento do sarcômero. Larzul et al. (1997), entretanto, indicaram que a correlação fenotípica entre fibras musculares do Longissimus dorsi e a qualidade da carne é de baixa a moderada.

A análise da correlação aponta que o número de células está relacionado positivamente com a perda de água por gotejamento e com o valor de $\mathrm{L}^{*}$ e negativamente com o diâmetro das fibras musculares, sugerindo que esses animais apresentam carne mais clara e com maior perda de água no gotejamento e fibras de menor diâmetro. Esses resultados identificam-se com as observações de Larzul et al. (1997) e de Ryu e $\operatorname{Kim}(2005)$, onde o número de fibras musculares apresentou correlação positiva com a perda de água por gotejamento e com o valor de L*. A análise indica também que músculos com maior porcentagem de célu- 
BOROSKY, ROCHA, OBA, PINHEIRO, BRIDIE SILVA

Tabela IV. Correlações entre número e diâmetro das células musculares, comprimento do sarcômero (Comp. sarc.) e tipo de células (glicolíticas, oxidativas e intermediárias) com as características de qualidade de carne: marmoreio, perda de água por gotejamento (PAG), e avaliação da cor (a), (b) e (L*)no músculo L. dorsi de suínos abatidos aos $100 \mathrm{~kg}$ de peso vivo. (Correlation of number and diameter of muscular cells, sarcomere length and fiber type (glicolitic, oxidative and intermediate) with the meat quality characteristics: marble effect, drip loss and meat color (a), (b) and $\left(\mathrm{L}^{*}\right)$ in the $L$. dorsi muscle of swine slaughtered at $100 \mathrm{~kg}$ of body weight).

\begin{tabular}{lcccccc}
\hline & Número & Diâmetro & Comp. sarc. & glicolíticas & oxidativas & intermediárias \\
\hline Número de células & 1 & $-0,33$ & $-0,28$ & 0,28 & $-0,25$ & $-0,18$ \\
Diâmetro celular & - & 1 & 0,12 & 0,14 & 0,01 & $-0,16$ \\
Comprimento sarcômero & - & - & 1 & $-0,14$ & $0,51^{* *}$ & $-0,16$ \\
Células glicolíticas & - & - & - & 1 & $-0,53^{* *}$ & $-0,84^{* *}$ \\
Células oxidativas & - & - & - & - & 1 & 0,13 \\
Células intermediárias & - & - & - & - & - & 1 \\
Marmoreio & $-0,18$ & $-0,45$ & - & $0,47^{* *}$ & $-0,28$ & $-0,38$ \\
PAG & $0,24^{* *}$ & $-0,27$ & - & $-0,20$ & 0,01 & 0,24 \\
a & $-0,13$ & $-0,46$ & - & 0,10 & $-0,36$ & 0,11 \\
b & 0,18 & $-0,12$ & - & 0,11 & $-0,35$ & 0,09 \\
L $^{*}$ & $0,34^{* *}$ & $-0,10$ & - & 0,08 & $-0,17$ & 0,02 \\
\hline
\end{tabular}

${ }^{* *} p<0,05$

las glicolíticas apresentam maior taxa de marmoreio, contrariando o conceito de que animais com mais fibras glicolíticas são mais musculosos e, portanto, têm menos habilidade para depositar gordura intramuscular, determinando taxas de marmoreio inferiores (Ashmore et al., 1972; Powel e Aberle, 1981; Larzul et al., 1997; Wegner et al., 2000).

Embora seja possível a manipulação do teor de gordura intramuscular através de recursos genéticos ou pela alimentação, existem pesquisas relacionando essa característica com parâmetros metabólicos musculares. Alasnier et al. (1996), estudando em coelhos os aspectos metabólicos do músculo com as características da gordura intramuscular, observaram que músculos com mais fibras glicolíticas tinham menor quantidade de lipídeos totais, triglicerídeos e colesterol que músculos com perfis mais oxidativos. Esta proposição também é valida para a espécie suína, sendo inclusive mais freqüente a porcentagem de células glicolíticas em animais portadores de do gen halotano, que apresentam maior deposição muscular (Essén-Gustavsson et al., 1992). Este quadro, porém, não coincide com os resultados obtidos, permitindo sugerir que provavelmente a correlação positiva observada entre as características tenha sido mais influenciada por outro fator relacionado com a deposição de gordura intramuscular que pela presença de fibras musculares glicolíticas.

Também houve correlação positiva entre o comprimento do sarcômero e a porcentagem de fibras oxidativas, mas não foi identificada qualquer relação destas características com as propriedades sensoriais avaliadas.

Segundo Serra et al. (1998), a porcentagem de fibras oxidativas está relacionada com a maciez da carne e o encurtamento do sarcômero é responsável pelo endurecimento da carne (Pardi et al., 2001). Assim, músculos com maior porcentagem de fibras oxidativas provavelmente apresentam menor encurtamento de sarcômero, preservando a maciez da carne.

Finalmente, não foram observadas

Archivos de zootecnia vol. 59, núm. 226, p. 284. 


\section{CARACTERÍSTICAS DAS FIBRAS MUSCULARES E A QUALIDADE DA CARNE SUÍNA}

correlações entre as características de qualidade de carne e o diâmetro da fibra muscular. Todavia, existem controvérsias sobre o tema. Rehfeldt et al. (2000) observaram que o aumento do diâmetro celular diminui a capacidade de retenção de água, enquanto que Gondret et al. (2006) não observaram influência do diâmetro das fibras musculares sobre a característica perda de água por gotejamento.

\section{CONCLUSÃO}

Pode-se concluir que o número e o tipo de fibras que compõem o músculo estão

\section{BIBLIOGRAFIA}

Alasnier, C., Rémignon, H. and Gandemer, G. 1996. Lipid characteristics associated with oxidative and glycolytic fibres in rabbit muscles. Meat Sci., 43: 213-224.

Ashmore, C.R., Tompkins, G. and Doeer, L. 1972. Postnatal development of muscle fiber types in domestic animals. J. Anim. Sci., 34: 37-41.

Boccard, R., Buchter, L., Cassels, E., Cosentino, E., Dransfield, E., Hood, D., Joseph, R., Mac Dougall, D., Rhodes, D., Schon, I., Tinbergen, B.J. and Tourailee, C. 1981. Proceedings for measuring meat quality characteristics in beef production experiments. Livest. Prod. Sci., 8: 385-397.

Dal Pai, V., Silva, D.P.M., Berto, D.A. and Curi, P.R. 1997. Fiber-type composition of skeletal muscle tissue in different breeds of pigs (Sus scrofa). Braz. J. Morphol. Sci., 14: 29-35.

Dwyer, C.M., Fletcher, J.M. and Stickland, N.C. 1993. Muscle cellularity and postnatal growth in the pig. J. Anim. Sci., 71: 33-39.

Essén-Gustavsson, B., Karlström, K. and Lundström, K. 1992. Muscle fiber characteristics and metabolic response at slaughter in pigs of different halothane genotypes and their relation to meat quality. Meat Sci., 31: 1-11.

Ezekwe, M.O.E. and Martin, R.J. 1975. Cellular characteristics of skeletal muscle in selected strains of pigs and mice and the unselected controls. Growth, 39: 95-106.

Gil, M., Gispert, M., Klont, R., Sosnicki, A. and Plastow, G. 2006. Metabolic and contractile relacionados com as características de qualidade da carne. Animais com maior número de fibras musculares têm menor taxa de gordura intramuscular e apresentam carne com maior luminosidade e com menor capacidade de retenção de água.

Não foi observada correlação entre número de fibras musculares e a freqüência de fibras glicolíticas. Esse resultado indica a necessidade de outros estudos na avaliação histoquímica para melhorar o entendimento da relação entre o número de células e a freqüência de fibras que compõem a musculatura dos suínos.

characteristics of muscles Longissimus thoracis and Semimembranosus from two porcine lines. Arch. Tierz., 49: 26-30.

Gondret, F., Lefaucheur, L., Juin, H., Louveau, I. and Lebret, B. 2006. Low birth weight is associated with enlarged muscle fiber area and impaired meat tenderness of the Longissimus muscle in pigs. J. Anim. Sci., 84: 93-103.

Handel, S.E. and Stickland, N.C. 1988. Catch-up growth in pigs: a relationship with muscle cellularity. Anim. Prod., 47: 291-295.

Heinemann, R.J.B., Pinto, M.F. e Romanelli, P.F. 2003. Fatores que influenciam a textura da carne de novilhos Nelore e cruzados LimousinNelore. Pesqui. Agropecu. Bras., 3: 963-971.

Irgang, R. 1997. Influência genética sobre o rendimento e a qualidade da carne em suínos. Anais do Congresso Brasileiro de Veterinários. Especialistas em Suínos, 1: 145-151.

Larzul, C., Lefaucheur, L., Ecolan, P., Gogue, J., Talmant, P., Sellier, P., Le Roy, P. and Monin, G. 1997. Phenotypic and genetic parameter for Longissimus muscle fiber characteristics in relation to growth, carcass, and meat quality traits in large white pigs. J. Anim Sci., 75: 31263137.

NRC. 1998. Nutrient Requirements of Swine. $10^{\text {th }}$ ed. National Academy Press, Washington, DC. Pardi, M.C., Santos, I.F., Souza, E.R. e Pardi, H.S 2001. Ciência, higiene e tecnologia da carne. $2^{a}$ ed. Centro Editorial e Gráfico Universidade de Goiás. Goiânia. 623 pp. 


\section{BOROSKY, ROCHA, OBA, PINHEIRO, BRIDI E SILVA}

Powell, S.E. and Aberle, E.D. 1981. Skeletal muscle and adipose tissue cellularity in runt and normal birth weight swine. J. Anim. Sci., 52: 748-756.

Rehfeldt, C., Fielder, I., Dietl, G. and Ender, K. 2000.

Myogenesis and postnatal skeletal muscle cell growth as influenced by selection. Livest. Prod. Sci., 66: 177-188.

Ryu, Y.C. and Kim, B.C. 2005. The relationship between muscle fiber characteristics, postmortem metabolic rate, and meat quality of pig Longissimus dorsi muscle. Meat Sci., 71: 351357.

Seidman, S.C., Crouse, J.D.E. and Mersmann, H.J. 1989. Carcass, muscle and meat characteristics of lean and obese pigs. J. Anim. Sci., 67: 29502955.

Serra, X., Gil, F., Perez-Enciso, M., Oliver, M.A., Vazquez, J.M., Gispert, M., Daz, I., Moreno, F., Latorre, R. and Noguera, J.L. 1988. A comparison of carcass, meat quality and histochemical characteristics of Iberian (Guadyerbas line) and Landrace pigs. Livest. Prod. Sci., 56: 215223.

Silva Sobrinho, A.G., Purchas, R.W., Kadim, I.T. e
Yamamoto, S.M. 2005. Características de qualidade da carne de ovinos de diferentes genótipos e idades ao abate. Rev. Bras. Zootecn., 34: 1070-1078.

Stickland, N.C. 1996. Roles de la génétique et de l'environnement dars la variabilité du developpement musculaire chez le pord et le cobaye. INRA Prod. Anim., 9: 216-217.

UFV.1997. SAEG. Sistema de análises estatísticas e genéticas. Versão 7.1. Universidade Federal de Viçosa. Viçosa, MG. 150 pp.

Veríssimo, S., Duarte, F.B., Mendonça, G.A., Campos, D.I., Pinto, R.O.C., Oliveira, R.R., Perin, F.B. Batista, D.F.A., Braga, T.F., Miranda, N.C., Freitas, P.F.A., Antunes, R.C., Arantes, V.M. e Beletti, A. 2008. Estudo ultraestrutural de fibras musculares de Longissimus dorsi e Semimembranaceo em suínos Large White... Anais do XXV Congresso Brasileiro de Medicina Veterinária, R1076-1081.

Wegner, J., Albrecht, E., Fielder, I., Teuscher, F., Papstein, H.J. and Ender, K. 2000. Growth and breed-related changes of muscle fiber characteristics in cattle. J. Anim Sci., 78:148-1496.

Archivos de zootecnia vol. 59, núm. 226, p. 286. 